The genus Diplocentrum Lindl., distributed in India and Sri Lanka, comprises only two species viz., $D$. recurvum Lindl. and $D$. congestum Wight (Misra 2007). Of these, $D$. congestum is endemic to Kerala OPEN ACCESS and Karnataka states (the Western Ghats) and $D$. recurvum is distributed in southern India (Andhra Pradesh, Karnataka, Kerala and Tamil Nadu) and Sri Lanka. During a recent floristic exploration in the Horsley Hills of Chittoor District of Andhra Pradesh, an interesting orchid population was discovered with attractive purple flowers. On critical examination, this orchid was identified as Diplocentrum recurvum, the Recurved Double Spur Orchid. After a thorough perusal of the relevant literature (Fischer 1928; Ramakrishna 1997; Madhavachetty et al. 2008; Misra et al. 2008; Raju et al. 2008) revealed that an earlier record of this species from the Horsley Hills of Andhra Pradesh dated back to July 1884 by J.S. Gamble (Field no. 15033) and May, 1904 by C.E.C. Fischer (Field no. 4353). Since then, there had been no collection of this species from the state. Therefore, the present record comes after a gap of over 100 years. The present paper is provided with nomenclatural citation, taxonomic description, phenology, distribution pattern with maps and photographic plates (Images 1-3). The specimens are deposited at BSID (Botanical Survey of

\section{A RE-COLLECTION OF DipLOCENTRUM RECURVUM LINDL. (ORCHIDACEAE) AFTER A LAPSE OF 100 YEARS OR MORE FROM ANDHRA PRADESH, INDIA}

\author{
Mitta Mahendranath ${ }^{1}$, Kummara Madhava Chetty ${ }^{2}$ \& \\ Kothareddy Prasad ${ }^{3}$ \\ 1,2 Department of Botany, Sri Venkateswara University, Tirupathi, \\ Andhra Pradesh 517501, India \\ ${ }^{3}$ Botanical Survey of India, Deccan Regional Centre, Plot No. 366/1, \\ Attapur, Hyderguda, Hyderabad, Telangana 500048, India \\ ${ }^{1}$ mitta.mahendranath@gmail.com, ${ }^{2}$ madhavachetty@gmail.com, \\ ${ }^{3}$ prasad.orchids@gmail.com (corresponding author)
}

India, Deccan Regional Centre, Hyderabad) \& SVUTY (Sri Venkateswara University, Tirupati) (Images 4-5).

\section{Diplocentrum recurvum Lindl.,}

Edwards's Bot. Reg. 18: t. 1522. 1832; Hook. f., Fl. Brit. India 6: 78. 1890; Misra, Orchids India 295. 2007; C.E.C. Fisch. in J.S. Gamble, Fl. Madras 3: 1449. 1928; Ramakrishna in Pullaiah, Fl. Andhra Pr. 3: 938. 1997; Misra et al., Bull. Bot. Surv. India 50(1-4): 129-146. 2008. D. Iongifolium Wight, Icon. PI. Ind. Orient. 5: t. 1681. 1851 (Images 1,2).

Type: Wallich Cat. 733, sine loc.(K!)

Epiphytic herbs. Roots greenish-white, flattened, vermiform. Stems erect or pendulous, stout, thick, ca. $20 \mathrm{~cm}$ long, with short internodes, sheathed. Leaves
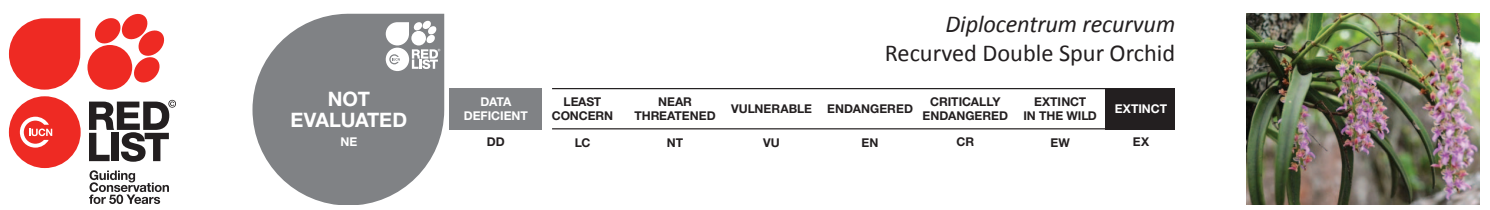

DOI: http://dx.doi.org/10.11609/JoTT.04172.7712-5

Editor: Pankaj Kumar, Kadoorie Farm and Botanic Garden, Tai Po, Hong Kong.

Date of publication: 26 August 2015 (online \& print)

Manuscript details: Ms \# 04172 | Received 14 October 2014 | Final received 06 August 2015 | Finally accepted 10 August 2015

Citation: Mahendranath, M., K.M. Chetty \& K. Prasad (2015). A re-collection of Diplocentrum recurvum lindl. (Orchidaceae) after a lapse of 100 years or more from Andhra Pradesh, India. Journal of Threatened Taxa 7(10): 7712-7715; http://dx.doi.org/10.11609/JoTT.04172.7712-5

Copyright: (c) Mahendranath et al. 2015. Creative Commons Attribution 4.0 International License. JoTT allows unrestricted use of this article in any medium, reproduction and distribution by providing adequate credit to the authors and the source of publication.

Funding: SERB-DST-NO. SB/YS/LS-270/2013, dated 13 May, 2014, New Delhi \& UGC-BSR-R.O.C.UGC.I(6)/RFSMS/Botany/2013, dated 2 October 2013, New Delhi.

Competing interests: The authors declare no competing interests.

Acknowledgements: Our grateful thanks to the Director, Botanical Survey of India, Kolkata and scientific staff of Botanical Survey of India, Deccan Regional Centre, Hyderabad for providing specialities and encouragement, and the third author gratefully acknowledges the financial assistance from the Department of Science and Technology, New Delhi. 

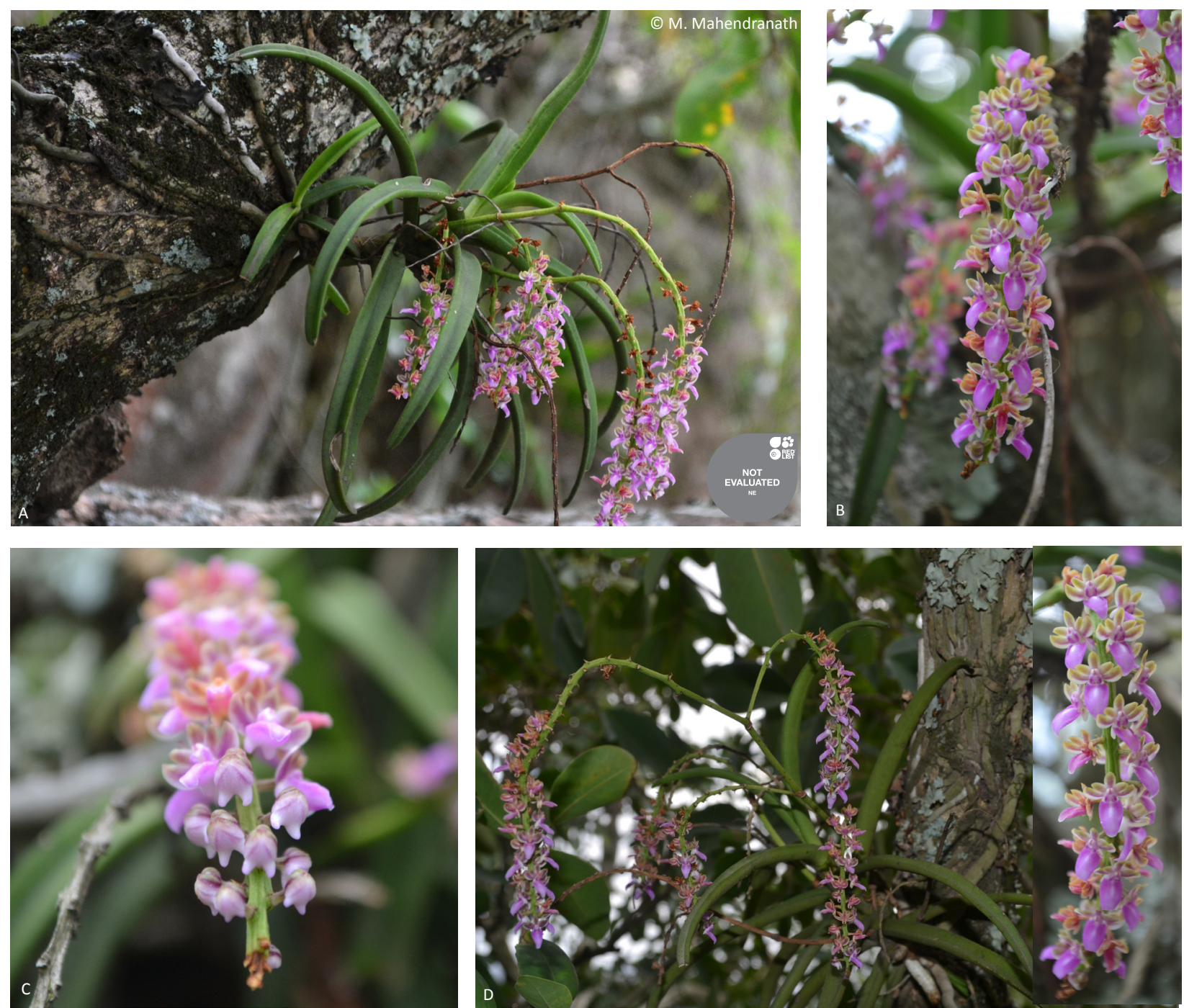

Image 1. Recurved Double Spur Orchid Diplocentrum recurvum

A - habit; B - Part of inflorescence; C - Close up of flowers; D - Lip with two spurs.

distichous, coriaceous, recurved, sessile, linear, 8-14 x $0.4-0.6 \mathrm{~cm}$, unequally bilobed at apex. Inflorescence axillary, longer than leaves, ca. $20 \mathrm{~cm}$ long, manyflowered panicles. Floral bracts minute, triangular, ca. $1 \times 1 \mathrm{~mm}$, acute, persistent. Pedicel with ovary short, ridged, 5-6 mm long. Flowers small, rose pink or brownish tinged with pink, ca. $6 \mathrm{~mm}$ across, widely opening. Sepals subequal; dorsal sepal erect, oblongovate, 2.6-3 x 1.6-1.8 mm, acute, 1-veined; lateral sepals falcately obliquely obovate-oblong, 3-3.4 x 2-2.2 $\mathrm{mm}$ broad, acute, 3-veined. Petals oblong-ovate, 2.6 x $1.8 \mathrm{~mm}$, acute, 1-veined. Lip sessile, oblong-ovate, 4.2-4.5 mm long, margins curved, 2-spurred; disk with a median thick fleshy ridge; spurs short, collateral, conical, ca. $2 \mathrm{~mm}$ long, incurved. Column short, stout, clavate, ca. $1 \mathrm{~mm}$ long, without foot. Pollinia 2, yellow, ovoid.
Capsule pyriform, ca. $1.5 \mathrm{~cm}$ long, ribbed.

Specimens examined: 1026 (SVUTY), 09.iii.2013, India: Andhra Pradesh, Horsley Hills, Chittoor District, $1200 \mathrm{~m}$, coll. M. Mahendranath; 006417(BSID), 10.ix.2014, Horsley Hills, Chittoor District, 1250m, coll. K. Prasad; 15033 (CAL), vii.1884, Horsley Hills, Chittoor District, 4500ft (1,370m), coll. J.S. Gamble; 4353 (CAL), 19.v.1908, Horsley Hills, Chittoor District, 4300ft (1,310m), coll. C.E.C. Fischer (Image 3).

Flowering and Fruiting: May-September.

Habitat and Ecology: This species was found growing on dense moss-covered tree trunks in tropical open dry deciduous forests in Horsley Hills at an elevation range between 1100-1300 m; more abundant at 1200-1250 $\mathrm{m}$ and conspicuously absent below $1100 \mathrm{~m}$. Fifty-six mature individuals were found during the current survey 


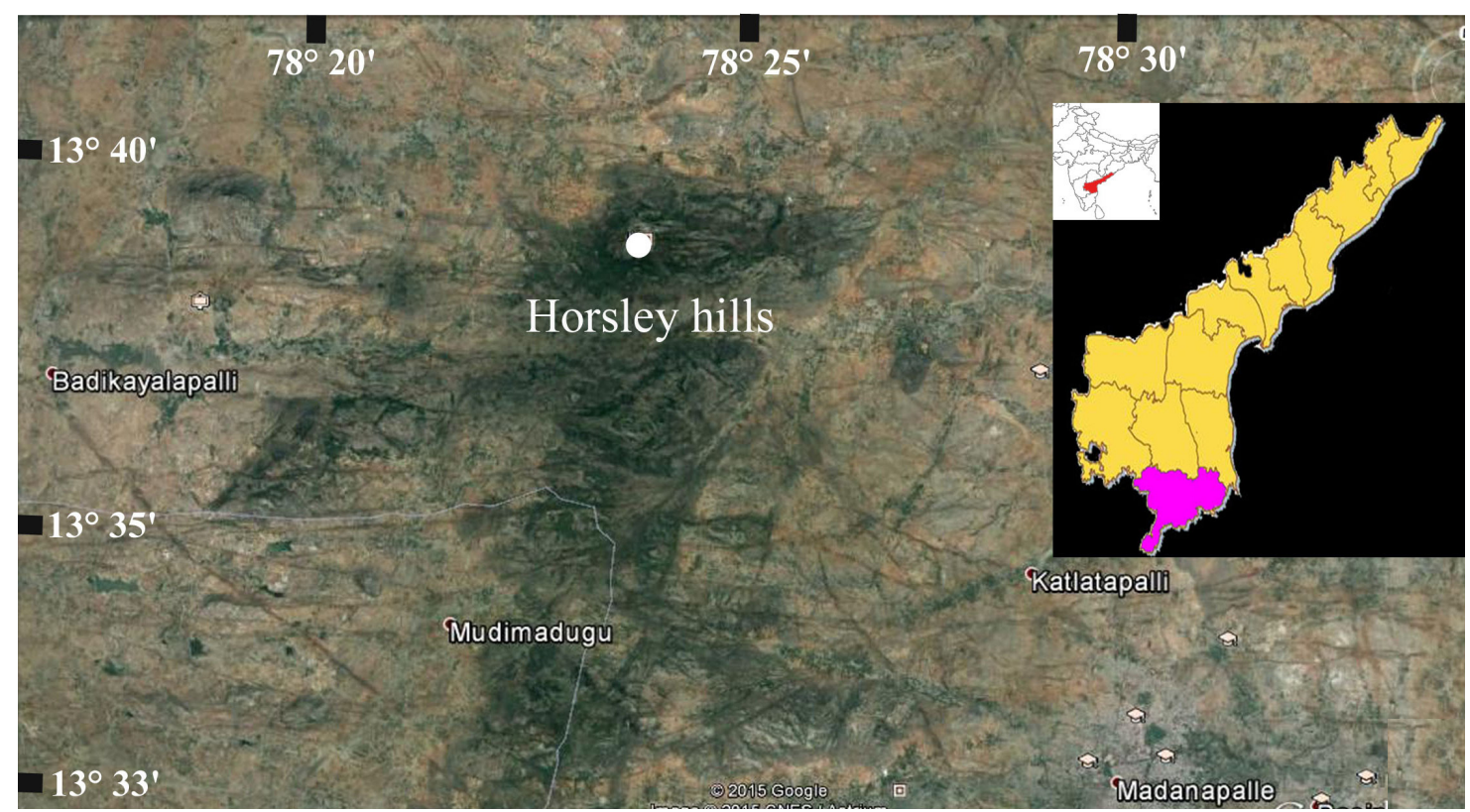

Image 2. Distribution map
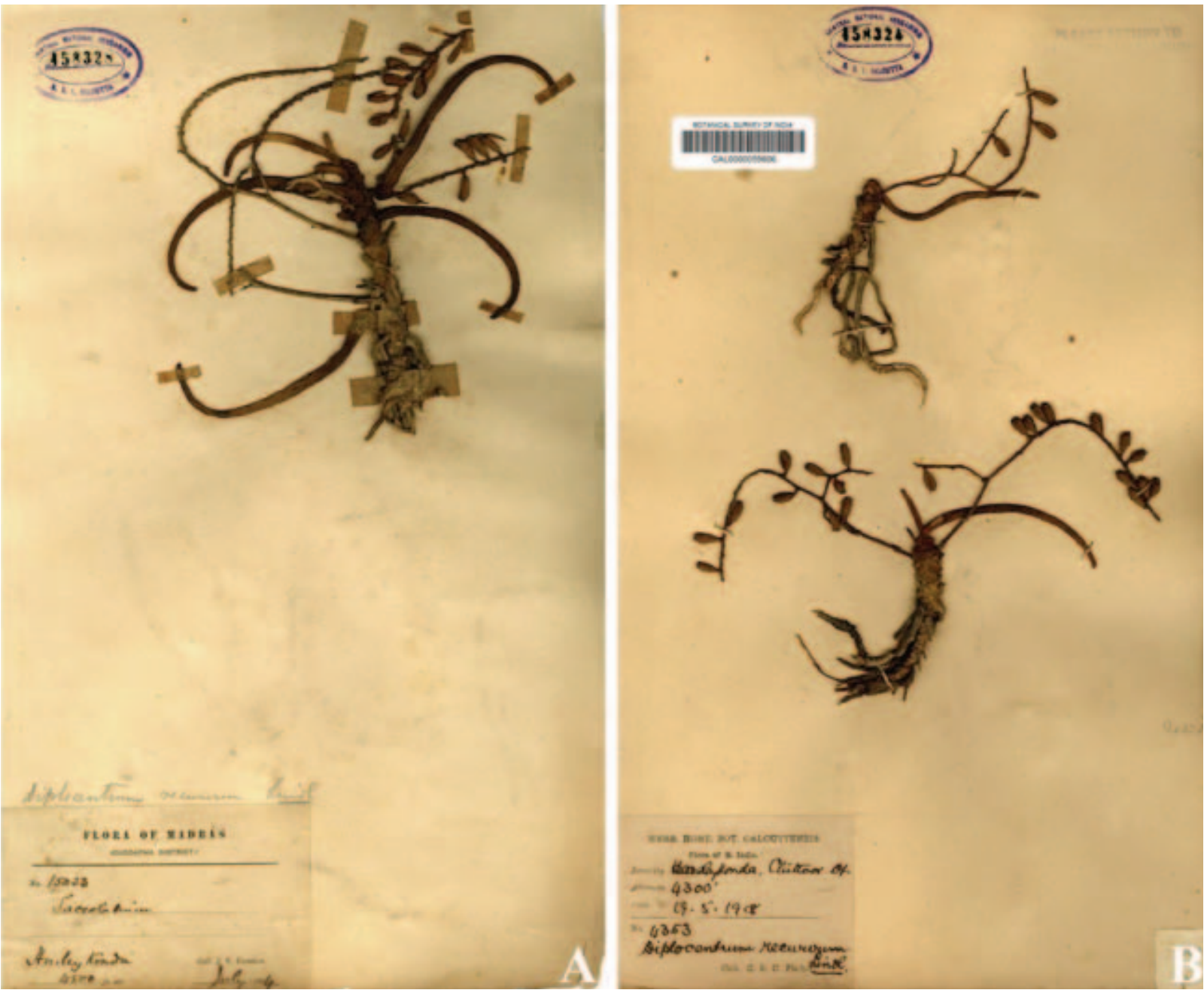

Image 3. A - J.S. Gamble collection (Field no. 15033-CAL); B - C.E.C. Fischer (Field no. 4353-CAL) collection 


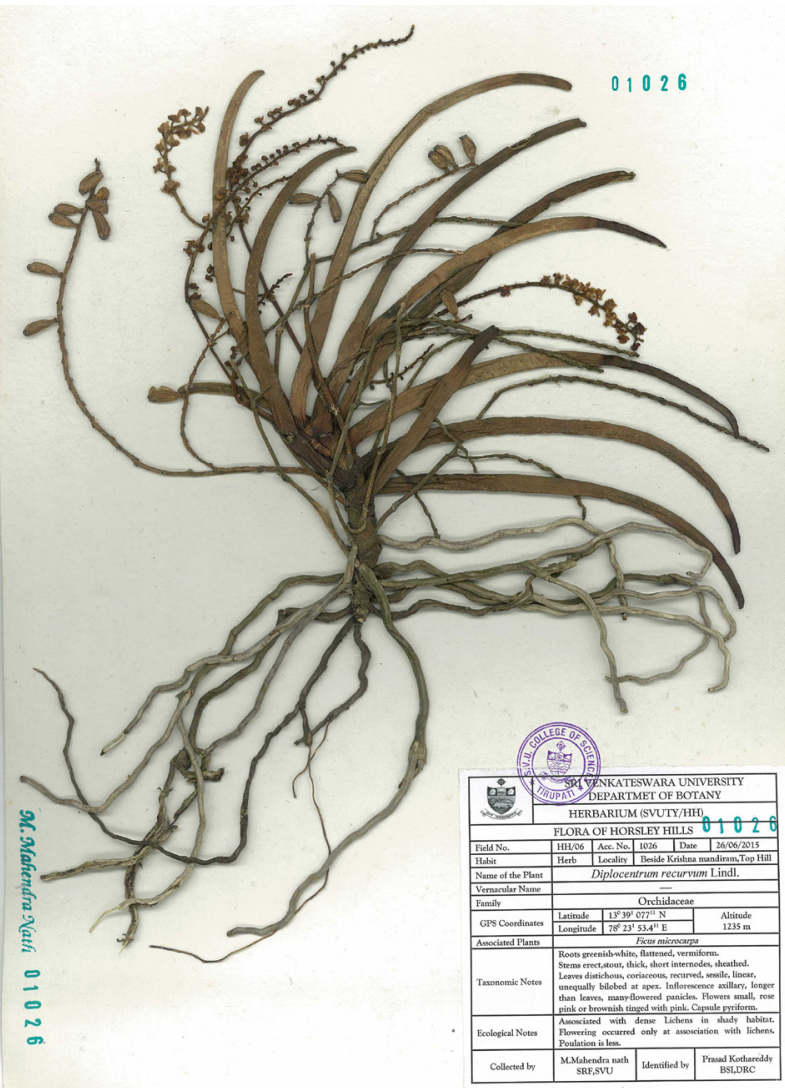

Image 4. Herbarium of Diplocentrum recurvum 1026 (SVUTY) deposited at Sri Venkateswara University, Tirupati

at Horsley Hills. Presently this species faces threats in the natural habitat due to anthropogenic activities like fuelwood collection by local people, and due to plantations and tourist activities.

Distribution: Sri Lanka and India: Andhra Pradesh (Horsley Hills, Chittoor District), Karnataka, Kerala and Tamil Nadu.

\section{References}

Fischer, C.E.C. (1928). Flora of The Presidency of Madras. Longon, 1399-1478pp.

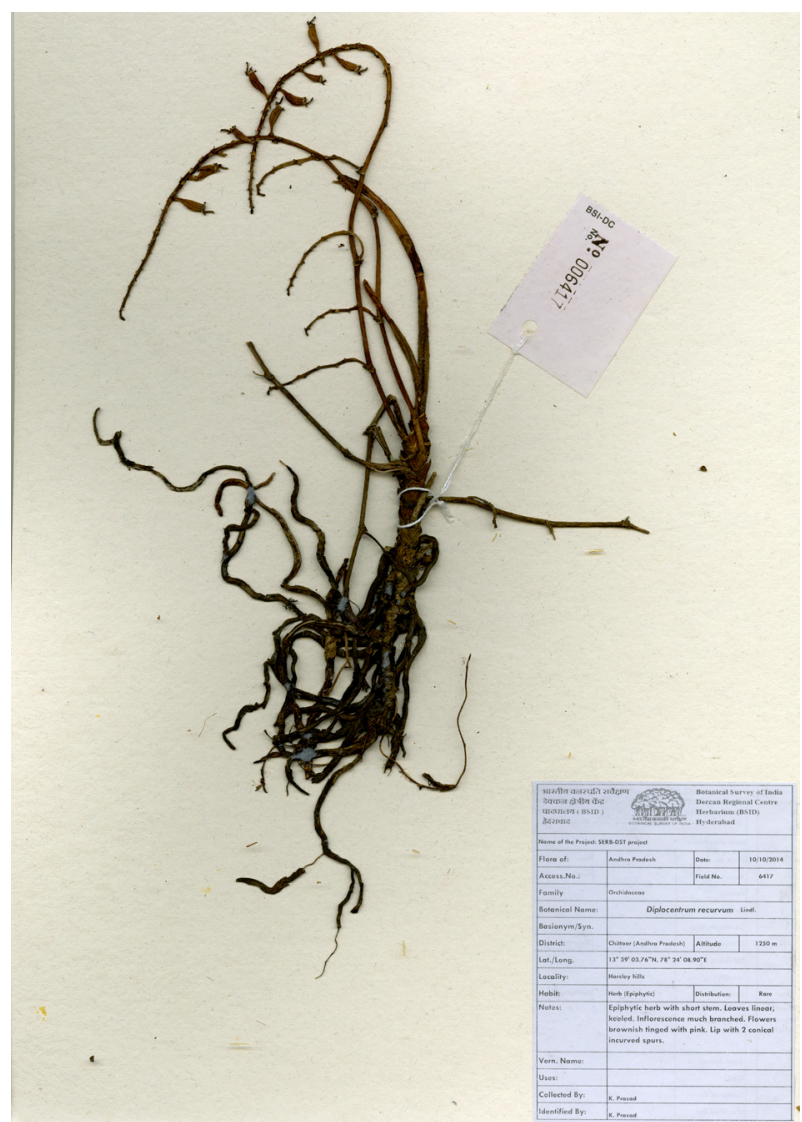

Image 5. Herbarium of Diplocentrum recurvum 006417(BSID) deposited at Botanical Survey of India, Deccan Regional Centre, Hyderabad

Madhavachetty, K., K. Sivaji \& K.T. Rao (2008). Flowering Plants of Chittoor District, Andhra Pradesh. Students offset Printers, Tirupati, 338-339pp.

Misra, S. (2007). Orchids of India, A Glimpse. Bishen Singh Mahendra Pal Singh, Dehra Dun (India), 295pp.

Misra, S., S.P. Panda \& D. Sahoo (2008). Orchid flora of Andhra Pradesh. Bulletin of Botanical Survey of India 50(1-4): 129-146.

Raju, V.S., C.S. Reddy, K.N. Reddy, K.S. Rao \& B. Bahadur (2008). Orchid Wealth of Andhra Pradesh. Proceedings Andhra Pradesh Akademi of Sciences, Hyderabad 12(1\&2): 180-192.

Ramakrishna, K.N. (1997). Orchidaceae, pp. 929-961. In: Pullaiah, T. (ed.). Flora of Andhra Pradesh - Vol. 3. Scientific Publishers, Jodhpur, 938pp. 